\title{
A TRILHA DO PARQUE ECOLÓGICO BOSQUE DOS PAPAGAIOS COMO ESPAÇO NÃO - FORMAL DE APRENDIZAGEM DA ORGANOGRAFIA VEGETAL
}

\author{
The Papagaios Grove Ecological park trail as a formal learning place for \\ plant organography
}

\author{
Esterline Félix dos Reis (felix.ester@hotmail.com) \\ Mestranda no Programa de Mestrado Profissional em Ensino de Ciências da Universidade Estadual de \\ Roraima (UERR). \\ Rodrigo Leonardo Costa de Oliveira (rodrigo@uerr.edu.br) \\ Mestrado em Botânica pela UFRPE, e doutorado em Botânica pelo INPA. \\ Professor do Curso de Ciências Biológicas e do Programa de Pós-graduação em Ensino de Ciências da \\ Universidade Estadual de Roraima (UERR). \\ Ivanise Maria Rizzatti (niserizzatti@gmail.com) \\ Mestrado e doutorado em Química pela Universidade Federal de Santa Catarina (UFSC). \\ Professora e Coordenadora do Programa de Mestrado Profissional em Ensino de Ciências da \\ Universidade Estadual de Roraima (UERR).
}

Resumo: Este artigo resume-se a uma prática realizada durante a disciplina de Organografia Vegetal (OV) do curso de Licenciatura em Ciências Biológicas da Universidade Estadual de Roraima (UERR), e teve como objetivo investigar a contribuição da trilha ecológica do Parque Ecológico Bosque dos Papagaios, enquanto espaço não formal de ensino, para o estudo de Organografia Vegetal. A metodologia consistiu-se de uma pesquisa de campo do tipo qualitativa. A coleta de dados baseou-se na observação direta durante a visita guiada realizada no mês de março de 2019 com 26 estudantes do terceiro período do curso de Licenciatura em Ciências Biológicas, e aplicação de um questionário contendo sete questões subjetivas, com intuito de compreender as percepções dos estudantes sobre a contribuição do espaço visitado para o estudo de Organografia Vegetal. O Bosque dos Papagaios enquanto espaço não formal de ensino, e pelo fato de ser um ambiente natural repleto de plantas nativas e exóticas com localização urbana na cidade de Boa Vista e aberto à visitação, possibilitou a interação dos estudantes com o conteúdo a ser aprendido, permitindo que conhecessem exemplares de espécies pelo nome científico e entender a relação de certas características com as espécies vegetais.

Palavras-chave: Organografia Vegetal, Espaços não formais, Trilha Ecológica, Ensino de Botânica.

Abstract: This article presents a practice conducted during a course of Plant Organography (OV) of the Degree in Biological Sciences of the State University of Roraima (UERR), and aimed to investigate the contribution of the ecological trail of the 
Papagaios Grove Ecological Park, as a non-formal education setting, for the study of Plant Organography. Methodology consisted of a qualitative field research. A data collection based on direct observation during a guided visit in March 2019, with 26 students from the third period of the Biological Sciences Degree, and the application of a questionnaire with seven subjective questions for understanding, as students' perceptions about the contribution of the visited space to the study of Plant Organography. The Papagaios Grove Ecological Park, as a non-formal education setting, and the fact that it is a natural environment of native and exotic plants located in the city of Boa Vista and open to visitors, allows students to interact with the content to be learned, allow them to know examples of species by scientific name and to understand a relationship of certain characteristics with plant species.

Keywords: Plant Organography, Non-formal Education setting, Eco Trail, Botany Teaching.

\section{INTRODUÇÃO}

A Organografia Vegetal (OV) é uma ciência voltada para o estudo da morfologia externa dos vegetais (VIDAL; VIDAL, 2006). Assim sendo, o ensino desta Ciência evidencia a necessidade de explorar ambientes naturais para o enriquecimento da dinâmica de aprendizagem, possibilitando ao aluno a construção de conceitos enquanto interage com a realidade a sua volta. Nesta perspectiva, apontam-se como agentes colaboradores os espaços não formais, entendidos por Jacobucci (2008) como todo e qualquer espaço em que possa ocorrer uma prática educativa, podendo ser esses espaços institucionalizados ou não institucionalizados.

Sendo assim, o uso dos espaços não formais para o ensino desta disciplina representa segundo Reis, Ghedin e Silva (2014), um ponto de ancoragem por meio do qual podem ser divulgados conhecimentos necessários ao desenvolvimento da aprendizagem do estudante relacionados aos seres vegetais, elevando-se as possibilidades de construção de conceitos sobre a temática.

Nesse sentido, este artigo é resultado de uma visita guiada realizada no Parque Ecológico Bosque dos Papagaios, durante a disciplina de OV com estudantes regularmente matriculados no terceiro semestre do curso de Licenciatura em Ciências Biológicas da Universidade Estadual de Roraima (UERR). Enquanto graduandos de um curso de licenciatura, os mesmos estão se preparando para a docência, assim é importante que tenham a oportunidade de acesso a alguma metodologia diferenciada e 
que valorizem os espaços não formais, para que posteriormente, caso desejarem, inserilas em sua prática docente. As práticas diferenciadas em espaços não formais podem contribuir para que os estudantes relacionem prática e teoria por meio da manipulação das estruturas das plantas, e construir novos conhecimentos sobre a morfologia externa das plantas, objeto de estudo da OV.

Assim, o objetivo deste estudo foi investigar a contribuição da trilha ecológica do Bosque dos Papagaios, enquanto espaço não formal de ensino, para o estudo de OV.

\section{ORGANOGRAFIA VEGETAL}

No decorrer do curso de Licenciatura em Ciências Biológicas os graduandos tem acesso a inúmeras disciplinas de formação, dentre elas disciplinas na área de Botânica. A Botânica está voltada para o estudo das plantas e geralmente, presencia-se constante rejeição dos estudantes em virtude da complexidade dos conteúdos que possuem elevado teor específico (FRITZEN, 2019).

A disciplina de OV ofertada no Curso de Ciências Biológicas da UERR compreende uma carga horária de $60 \mathrm{~h}$, equivalente a três créditos no referido curso. Sendo comum ocorrerem aulas de campo em espaços não formais, como praças públicas, feiras livres e no Parque Ecológico Bosque dos Papagaios, apresentando composições de espécies vegetais com características próprias.

Nesses diferentes espaços não formais é possível observar o potencial paisagístico com a presença de árvores provenientes de outras regiões e que foram distribuídas no país, como o ipê-roxo [Handroanthus impetiginosus (Martius ex DC.) Mattos], oiti [Licania tomentosa (Benth.)] e a mungubarana [(Pachira aquatica Aubl.)], também ocorrente na Amazônia. E no Bosque dos papagaios, é possível observar espécies nativas do lavrado de Roraima, como por exemplo, caimbé (Curatella americana L.), mirixis (Byrsonima spp.), entre outras.

O lavrado de Roraima é encontrado na região nordeste do estado e compreende a maior área de savana natural da Amazônia brasileira com cerca de $43.000 \mathrm{~km}^{2}$ de área (BARBOSA; CAMPOS, 2011). O lavrado faz parte do complexo Rio Branco- 
Rupununi, que se estende da Venezuela até a República da Guiana (BARBOSA; FEARNSIDE, 2005), formando um grande mosaico de ecossistemas não-florestais (vegetação aberta com baixa densidade de árvores) e florestais, (matas de galeria e buritizais), com dominância de áreas de vegetação aberta (BARBOSA et al., 2007).

\section{TRILHA DO PARQUE ECOLÓGICO BOSQUE DOS PAPAGAIOS}

O Parque Ecológico Bosque dos Papagaios está localizado na área urbana do município de Boa Vista, capital do estado de Roraima (Figura 1), e possui uma área institucional de 12 hectares, tendo como destaque uma vegetação nativa com árvores de pequeno, médio e grande porte situado em meio ao lavrado. Por estar localizado dentro do contexto urbano, proporciona um ambiente agradável para interagir com a natureza (ARAÚJO JÚNIOR; SANTOS; OLIVEIRA, 2018) sendo mantido e administrado pela Secretaria Municipal de Gestão Ambiental e Assuntos Indígenas - SMGA.

O parque foi criado em $1^{\circ}$ de julho de 2009 , por meio do decreto $n^{\circ} 113-\mathrm{E}$, com inauguração ocorrida no dia 6 de julho de 2009, tendo como finalidade a difusão de práticas ambientais e experiências relevantes que visem à ampliação da conscientização da necessidade de conservação e recuperação ambiental (LAU, 2014). Segundo Souza, Reis e Rizzatti (2018, p. 415):

\footnotetext{
A implantação do bosque ocorreu a partir da execução de um Projeto intitulado "Nas Trilhas da Conservação", que tinha como objetivo sensibilizar a população acerca da importância da conservação do solo, da fauna e da flora, com vista à extinção dos problemas causados pelo acúmulo de resíduos sólidos no lugar. Sendo assim, uma equipe da Secretaria de Meio Ambiente da Prefeitura Municipal de Boa vista, passou a desenvolver ações diárias de educação ambiental, envolvendo estudantes das redes estadual, municipal e particular de ensino, além de buscar parcerias com universidades, institutos e centros de estudos localizados em Boa Vista.
} 


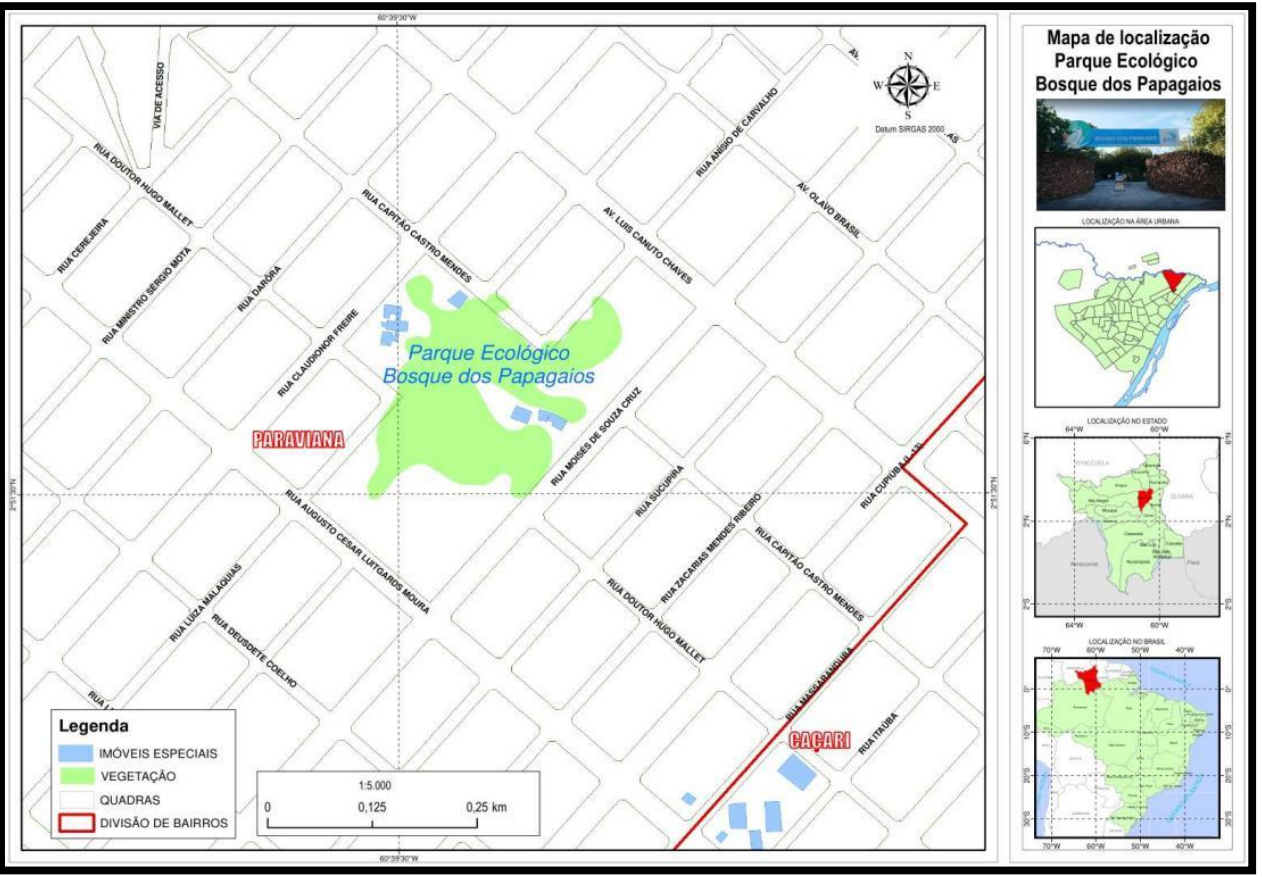

Figura 1. Localização do Parque Ecológico Bosque dos Papagaios. Fonte: Adriana de Souza Vanderley (2019).

No local encontram-se seis trilhas, que dão acesso a todas as partes do Bosque, sendo duas para caminhadas e quatro educativas, permitindo que o visitante possa percorrer todo o espaço em contato com a natureza, conhecendo de perto a vegetação e espécies da fauna nativa (ARAÚJO JÚNIOR; SANTOS; OLIVEIRA, 2018). Callegaro (2013) define as trilhas como um caminho no meio natural que promove a condução de pessoas entre alguns pontos.

Para Andretta et. al. (2006) as trilhas são percursos em um sítio natural, que propiciam explicações sobre o meio ambiente, flora, fauna, fenômenos naturais, usos e hábitos do local. $\mathrm{O}$ autor acrescenta que as trilhas são caminhos existentes ou estabelecidos, com diferentes formas, comprimentos e larguras, que possuam o objetivo de aproximar o visitante ao ambiente natural, ou conduzi-lo a um atrativo específico, possibilitando seu entretenimento ou educação através de sinalizações ou de recursos interpretativos.

Nesse sentido, a visita guiada ao espaço não formal educativo Bosque dos Papagaios propicia aos visitantes um convite a uma experiência de aprendizagem que colabora para a formação acadêmica dos licenciandos. Sendo relevante apresentar o entendimento que se tem sobre espaço formal e não formal. Jacobucci (2008, p. 56) 
afirma que o espaço formal "é o espaço escolar, que está relacionado às Instituições escolares da Educação Básica e do Ensino Superior, definidas na Lei de Diretrizes e Bases da Educação Nacional n 9394/96”. Enquanto os espaços não formais são aqueles onde uma prática educativa pode ser desenvolvida.

A autora acrescenta que esses espaços podem ser institucionalizados, quando são espaços regulamentados, com presença de estrutura técnica, tais como museus, zoológicos, jardins botânicos, planetários parques ecológicos, etc. Podendo ser ainda não institucionalizados quando estão relacionados aos espaços sem estrutura organizacional para práticas educativas, entre os quais, citam-se parques, praças, rios, lagos, ruas, entre outros (JACOBUCCI, 2008). Nesse sentido o Bosque dos papagaios é classificado como um espaço institucionalizado, em virtude de estar voltado para a realização de práticas educativas.

Marandino (2009) destaca a importância dos espaços não formais para o ensino, em virtude das possibilidades do desenvolvimento de práticas educativas, que buscam relacionar os conhecimentos que os alunos já possuem através de atividades motivadoras que colaboram para um novo aprendizado. Pin e Rocha (2017, p. 134) acrescentam que "os espaços educativos não formais representam instâncias difusoras de conhecimentos, catalisadores de motivação e interesse, tanto para alunos quanto para professores", pois promovem a dinamização do conhecimento, em que o professor utiliza-se do espaço não formal para possibilitar a aprendizagem, a formação de conceitos e desenvolvimento de pensamento científico.

Algo importante a ser pensado e observado é a possibilidade do professor conhecer o espaço não formal ao qual fará uso em sua prática educativa, para verificar a potencialidade do espaço pretendido para o objetivo da aula planejada, evitando surpresas desagradáveis e que possam comprometer o objetivo da visita guiada ou mesmo causar danos físicos aos estudantes presentes. Sendo relevante planejamento, organização e apoio da instituição de ensino. Assim, Cardoso (2019, p. 32) enfatiza que "o planejamento é um dos primeiros passos a ser dado, com critérios e levando em consideração os anseios da turma aliado ao tema trabalhado". Buscando motivá-los a fazer uso do espaço visitado para seu conhecimento. 


\section{METODOLOGIA}

A metodologia deste estudo é a pesquisa de campo de abordagem qualitativa, tendo como instrumento de coleta de dados a aplicação de questionário contendo sete questões direcionadas aos 26 estudantes do curso de Licenciatura em Ciências Biológicas da UERR, matriculados na disciplina de OV.

A pesquisa foi realizada no mês de março de 2019, após uma visita guiada pela trilha do Parque Ecológico Bosque dos Papagaios proporcionada pelo professor da disciplina de $\mathrm{OV}$ aos estudantes participantes da pesquisa. A escolha dos participantes do estudo ocorreu devido a pesquisadora estar realizando estágio de docência na disciplina citada

Os estudantes, participantes da pesquisa, foram informados que se tratava de um trabalho de pesquisa da disciplina de estágio supervisionado do Mestrado Profissional em Ensino de Ciências da UERR, cursada entre os meses de fevereiro a junho de 2019, e que seus nomes seriam mantidos em sigilo. Os questionários foram entregues pessoalmente aos estudantes na aula posterior à visita guiada. Os estudantes foram identificados pelos códigos: E1, E2, E3... E26.

A trilha percorrida foi a principal do Bosque para visitação proporcionando acesso as plantas nativas e exóticas do local, com duração de aproximadamente 60 minutos, devido às paradas programadas para abordagem das plantas presentes no local, perpassando ambientes como a entrada principal e trilha pavimentada.

A fim de verificar a influência da trilha percorrida sobre o entendimento relacionado à $\mathrm{OV}$, pontuaram-se os seguintes questionamentos: entendimento sobre espaço não formal; espaços não formais visitados anteriormente; percepções sobre a utilização da trilha do Bosque dos Papagaios; contribuição da visita guiada para a aprendizagem de conteúdos referentes à $\mathrm{OV}$; espécies vegetais presentes no espaço visitado, e a importância do espaço visitado para o ensino.

Antes da visita ocorrer os estudantes tiveram acesso as informações acerca de temáticas inseridas na disciplina, explanadas pelo professor, sendo elas: morfologia da 
raiz, do caule e da folha. A análise dos dados considerou a reflexão sobre as respostas e o que dizem autores como Jacobucci (2008) sobre a temática abordada.

\section{RESULTADOS E DISCUSSÕES}

Dos 26 estudantes participantes da pesquisa, 24 estão cursando o terceiro semestre e dois estão no quinto semestre do curso de Licenciatura em Ciências Biológicas. A faixa etária dos estudantes é entre 20 a 24 anos de idade.

A primeira questão abordada buscou saber qual o entendimento dos estudantes sobre espaço não formal, tendo obtido respostas como de E1 "o que foge do cotidiano, que não é monótono, uma aula diferente, fora de um ambiente que estamos acostumados". Evidenciando que o aluno compreende que o uso do espaço não formal está relacionado com a dinamização da aula, buscando proporcionar aos estudantes formas contextualizadas de compreender uma determinada temática. Nesse sentido, Oliveira et al. (2019) afirma que o ensino considerado potencializador do desenvolvimento da educação em Ciências, centra-se em possibilitar ao aprendiz produzir e criar a partir da interação com o que se pretende ensinar, e não apenas treinar e transferir conhecimento em um sentido unidirecional.

Por sua vez, os estudantes E12 e E18 apresentaram respostas incorretas, onde o primeiro mencionou que o espaço não formal é o espaço informal, demonstrando confusão conceitual, em virtude de os espaços informais serem diferentes dos espaços não formais, por serem espontâneos e ocorrerem de forma voluntária e sem objetivo avaliativo. O segundo citou a ausência de normas ou regras durante a execução de aulas em espaços não formais, sendo relevante esclarecer que para realizar aulas em espaços não formais é importante que haja regras bem definidas para não perder o objetivo da aula.

Neste sentido Gohn (2009) pontua que:

A educação formal é aquela desenvolvida nas escolas, com conteúdos previamente demarcados; a informal como aquela que os indivíduos aprendem durante seu processo de socialização - ocorrendo em espaços da família, bairro, rua, cidade, clube, espaços de lazer e entretenimento; nas igrejas; e até na escola entre os grupos de amigos; ou em espaços 
delimitados por referências de nacionalidade, localidade, idade, sexo, religião, etnia, sempre carregada de valores e culturas próprias, de pertencimento e sentimentos herdados (GOHN, 2009, p. 40).

Na segunda questão, buscou-se saber se os estudantes já visitaram algum espaço não formal no ensino fundamental, médio ou superior, e todos os estudantes afirmaram já ter feito alguma visita a um espaço não formal. Sendo as respostas apresentadas no Quadro 1.

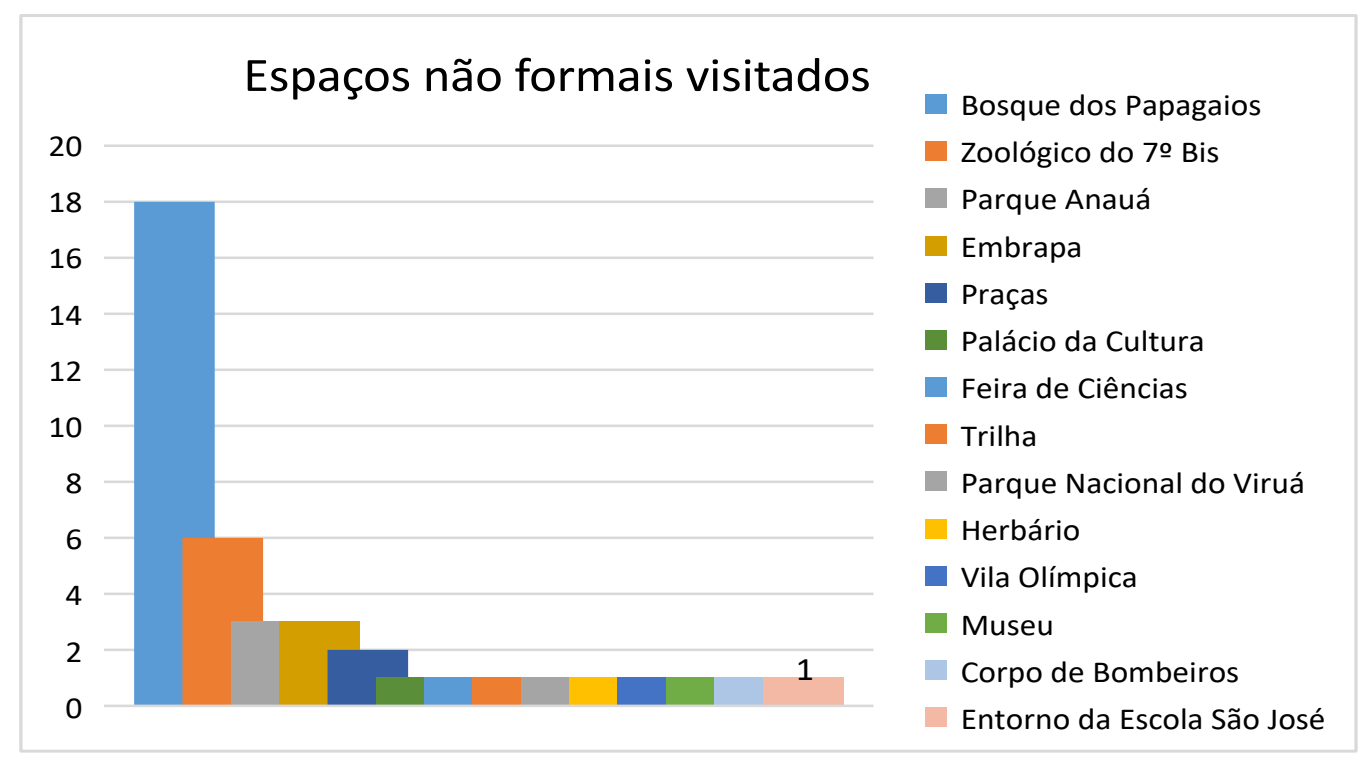

Quadro 1 - Espaços não formais visitados pelos estudantes da turma pesquisada.

Fonte: Esterline Reis (2019).

Ao analisar as respostas dos estudantes, percebeu-se que foram citados 14 diferentes espaços não formais educativos, dentre eles, espaços institucionalizados como a Embrapa, Herbário, Parque Nacional do Viruá, Zoológico do $7^{\circ}$ Bis, e espaços não institucionalizados como Praças e em torno da Escola Estadual São José, localizada na área central da capital. Dentre os espaços mais citados pelos estudantes estão o Bosque dos Papagaios, citado 17 vezes, o Zoológico do $7^{\circ}$ Bis mencionado seis vezes, Parque Anauá e Embrapa, ambos visitados por três dos 26 estudantes, e as praças foram citadas duas vezes.

Os demais foram citados apenas uma vez dentre os quais estão a Trilha, Feira de Ciências, Palácio da Cultura, entre outros. Percebe-se com isso a presença dos espaços 
não formais na vivência educacional dos estudantes, embora de forma tímida, visto que muitos professores encontram resistência em ultrapassar as paredes da sala de aula, no processo de ensino e aprendizagem. Resistência essa que limita as possibilidades de aprendizagem que podem ser ofertadas aos estudantes, focos centrais no processo educacional.

Desta forma, Lorenzetti e Delizoicov (2001, p. 7), destacam que "se a escola não pode proporcionar todas as informações científicas que os cidadãos necessitam, deverá, ao longo da escolarização, propiciar iniciativas para que os estudantes saibam como e onde buscar os conhecimentos que necessitam para a sua vida diária". Acrescentam ainda que, os espaços não formais tem a possibilidade de ampliação do conhecimento dos educandos contribuindo para o ganho cognitivo por parte do aprendiz.

$\mathrm{Na}$ terceira questão quando perguntados se era a primeira vez que visitaram o Bosque dos Papagaios, 13 estudantes afirmaram que sim, apresentando justificativas como "Porque não tinha conhecimento do local na capital" (E3) ou "Nunca me interessei" (E24). Entendendo-se desta forma que um quantitativo significativo dos estudantes nunca havia entrado antes no Parque Ecológico Bosque dos Papagaios (Figura 2), sendo a passeio ou através de uma visita guiada, estabelecendo-se assim, a necessidade de aproximação do parque com a comunidade em virtude de ser um espaço de aprendizagem rico e exuberante e de grande potencial para práticas educativas. 


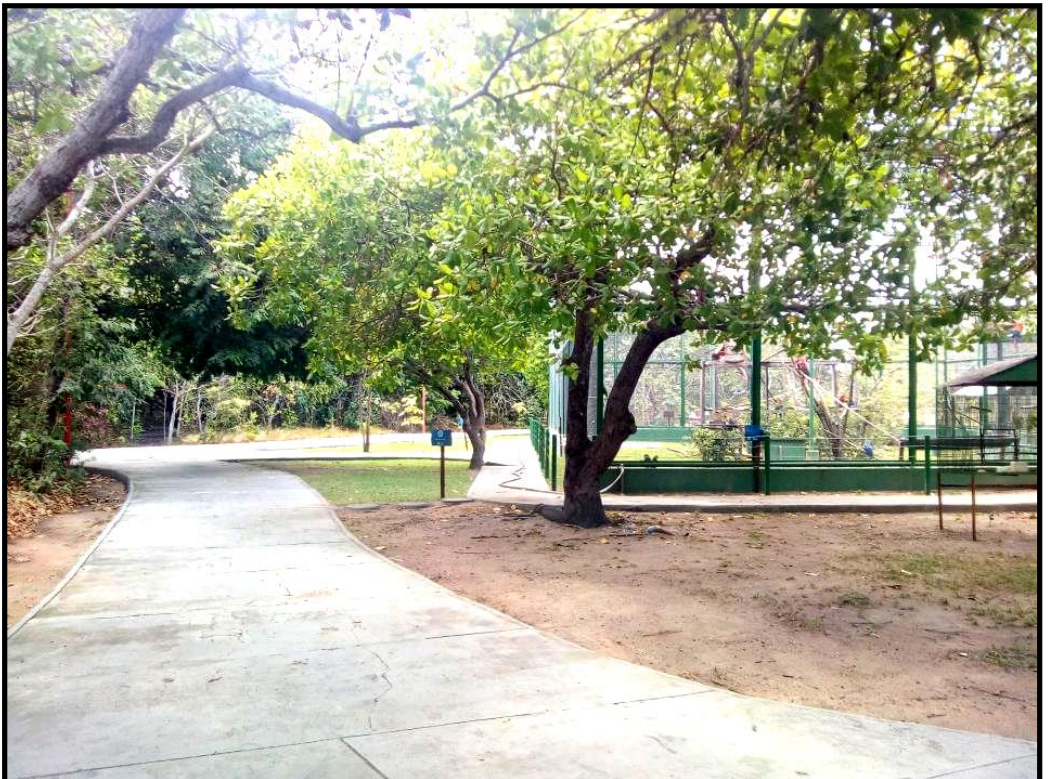

Figura 2. Imagem mostrando o início da trilha do Parque Ecológico Bosque dos Papagaios. Fonte: Esterline Reis (2019).

Oliveira (2019) refere que a parceria entre unidade de ensino e os espaços não formais possibilitam um maior significado aos estudos da ciência, por possuírem atrativos que podem despertar o interesse e o olhar científico do estudante, destacandose o papel do professor em mediar, estimular a curiosidade e o desejo pela ciência e possibilitando uma aproximação com o objeto a ser estudado, considerando que isso poderá acontecer se houver a mediação e a intencionalidade do professor.

Na quarta questão quando perguntado suas percepções a respeito da utilização da trilha do Bosque dos Papagaios para o ensino, E10 destacou que "é um meio em que se pode analisar e despertar a curiosidade dos estudantes nos permitindo estar em um local para aumentar o conhecimento", e E18 ressaltou que durante a trilha teve a possibilidade de aprender nomes de muitas espécies presentes no local. Percebeu-se que para os estudantes a experiência da trilha foi enriquecedora, ao permitir que desfrutassem de um ambiente natural em que pudessem interagir com as plantas enquanto estudavam, propiciando a construção de conceitos enquanto exploravam o espaço visitado (Figura 3). Colaborando na aprendizagem iniciada em sala de aula quando o professor explanou sobre as temáticas abordadas raiz, caule e folha. 
Vol. 2, n. 4. Set./Dez. 2019
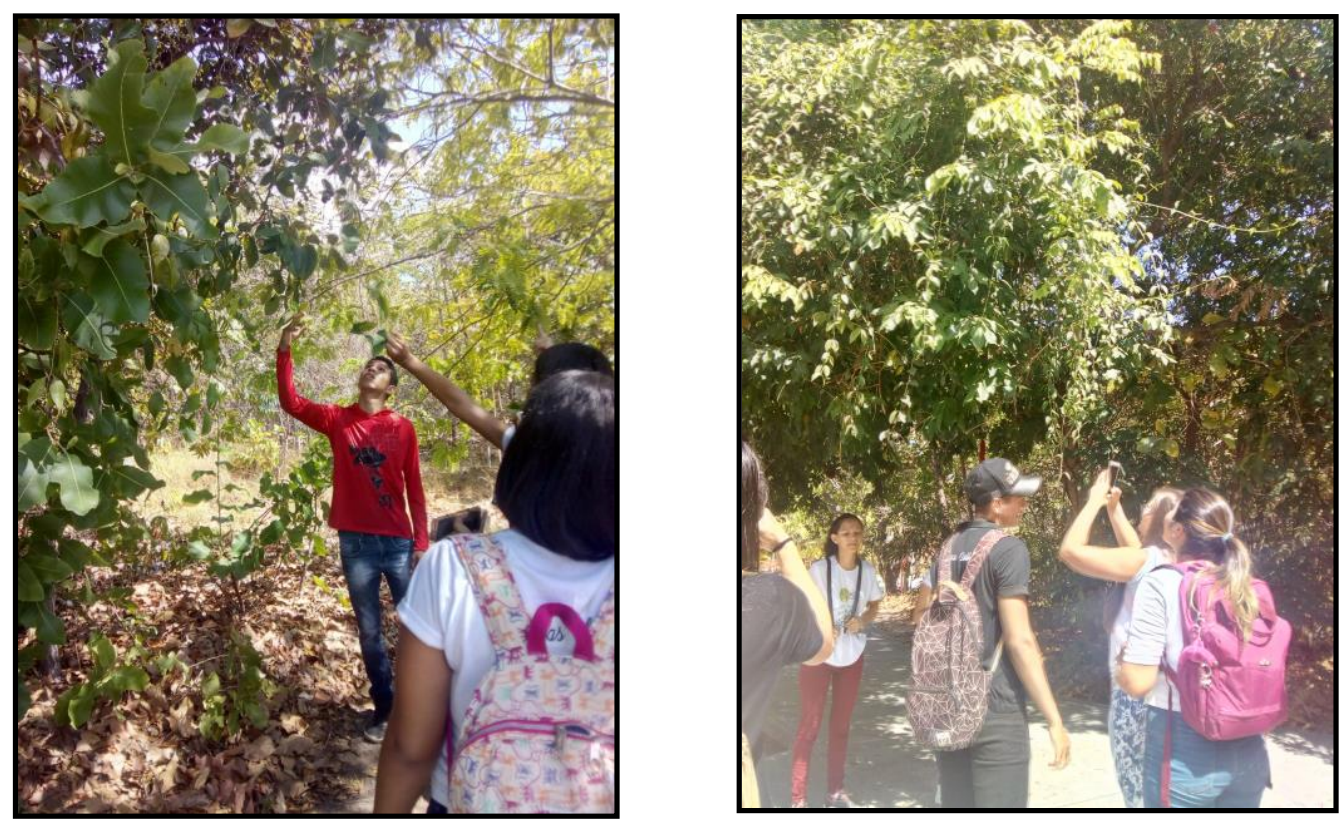

Figura 3. Imagens da visita guiada com os estudantes visualizando as plantas do local.

Fonte:Esterline Reis (2019).

Na quinta questão indagou-se sobre a relação da visita assistida com a disciplina de OV, onde E6 apontou que a aula possibilitou "esclarecer as dúvidas que ficam na cabeça durante as aulas teóricas, as pesquisas de campo ajudam bastante no ensino". Ressalta-se neste momento a parceria que pode existir entre os espaços formais e não formais, pois ambos são importantes e podem ser utilizados para complementar um ao outro, levando-se em consideração a temática, o objetivo da aula e o espaço não formal selecionado.

$\mathrm{Na}$ sexta questão solicitou-se que os estudantes citassem exemplares vegetais presentes no espaço visitado que mais lhes chamaram atenção (Quadro 2), tendo percebido que os estudantes citaram muitos exemplares diferentes, refletindo na relevância da visita para complementação do entendimento sobre a temática abordada. 


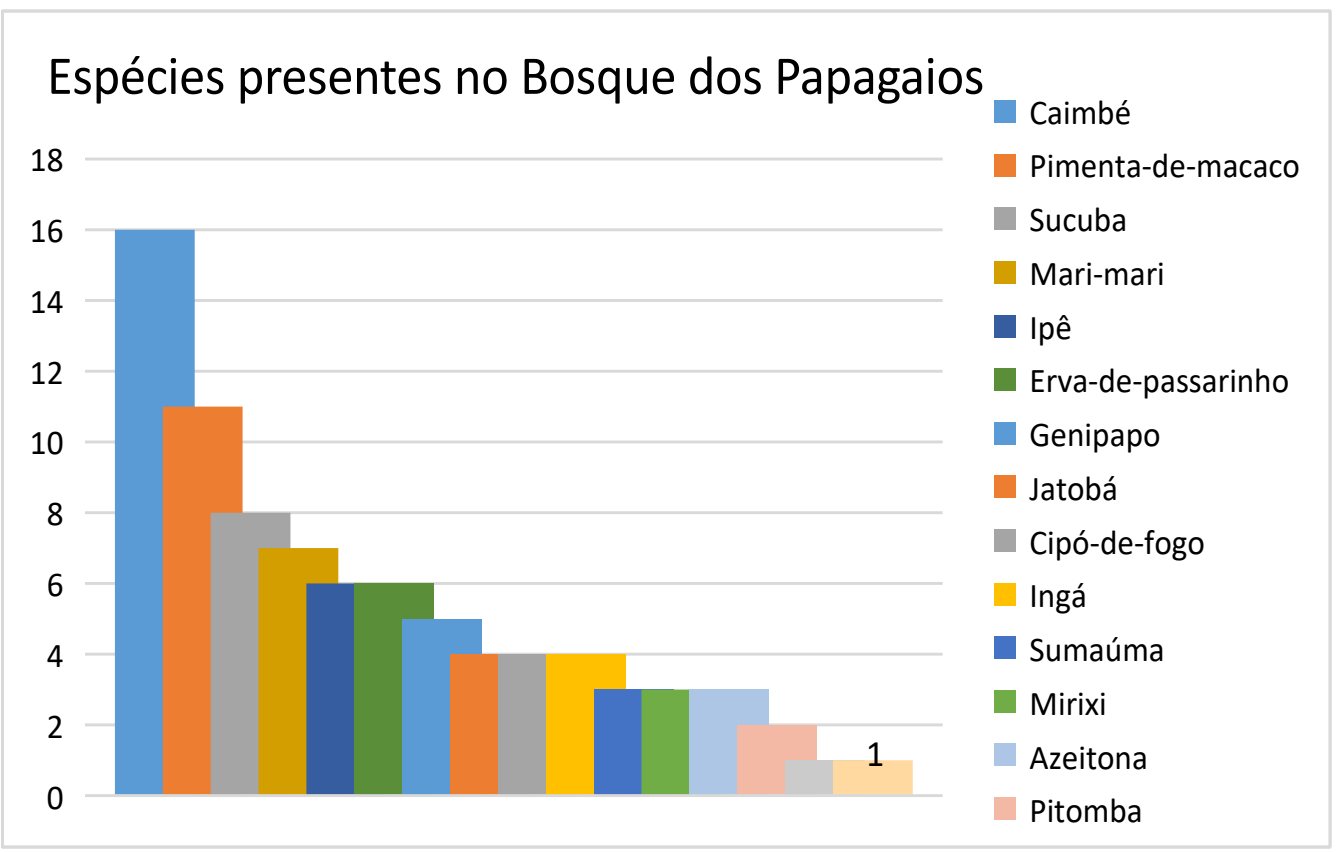

Quadro 2 - Exemplares de plantas avistadas durante a visita ao Bosque dos Papagaios.

Fonte: Esterline Reis (2019).

Foram citados pelos estudantes um total de 17 espécies diferentes avistadas durante o percurso por meio da trilha do Bosque dos Papagaios. Dentre as quais se destaca o Caimbé, citado por 16 dos 26 estudantes. Essa planta característica do lavrado roraimense se faz presente no local, e por meio da observação e tato, foi possível não somente ouvir a explicação sobre a característica da espécie, como também observar sua estrutura com presença de tronco retorcido e sentir a folha áspera, característicos da planta. Outra planta citada por muitos estudantes foi à pimenta-de-macaco, dada as peculiaridades da planta e formato do fruto que durante a visita deixou os estudantes curiosos. Percebendo-se, assim, que o contato com o ambiente natural possibilita ao estudante explorar o ambiente e nessa experiência aprender e relacionar esse aprendizado com outros saberes ou situações do cotidiano, podendo aplicar esse conhecimento em outras situações.

A sétima e última questão buscou-se verificar a importância de espaços como o Bosque dos Papagaios para o ensino. Tendo obtido respostas como a de A19 "mostra uma perspectiva diferente e que possivelmente em sala de aula não seja possível transpor". Para Rocha e Téran (2010, p. 54) "uma parceria entre a escola e espaços não- 
formais, pode representar uma oportunidade para a observação e problematização dos fenômenos de maneira menos abstrata”. Sendo possível perceber, que o estudante de licenciatura apreendeu a essência da visita assistida, tendo o professor da disciplina contribuído para aprendizagem de conteúdos relacionados à $\mathrm{OV}$, de maneira dinâmica e motivadora, que poderá se refletir no futuro dos que possivelmente se tornarão profissionais da educação.

A visita guiada ao Parque Ecológico Bosque dos Papagaios tornou-se relevante em virtude da exuberância do ambiente, possuindo em suas dependências plantas nativas e exóticas passíveis de serem vistas e apreciadas por meio de trilhas ecológicas, oferecendo aos visitantes um espaço livre para passeios, e quando organizada em uma atividade de ensino, também pode contribuir para o processo de aprendizagem.

\section{CONCLUSÕES}

A trilha ecológica do Parque Ecológico Bosque dos Papagaios, enquanto espaço não-formal de educação, contribuiu para o estudo e aprendizagem da Organografia Vegetal ao possibilitar a interação dos estudantes com as espécies vegetais do local. A atividade foi enriquecedora para os alunos não somente pela contemplação do conteúdo da disciplina, como também da própria visitação ao local, pois muitos estudantes nunca tinham frequentado ambientes como o Bosque dos Papagaios, e também por ter proporcionado o primeiro contato didático com as espécies locais do lavrado.

Por meio das trilhas os estudantes puderam observar plantas em seu habitat natural e estudar seus aspectos morfológicos. Dentre as quais, o caimbé (Curatella americana), pimenta-de-macaco (Xylopia aromatica), sucuba (Himatanthus drasticus), entre outras. Desta forma, verificou-se que o uso de espaços não-formais no ensino de Ciências representa estratégias que podem ser inseridas na prática pedagógica dos professores, em virtude de permitir que o estudante interaja com o conteúdo a ser aprendido elevando as potencialidades de aprendizagem. 
Soma-se a isso a importância de possibilitar aos estudantes de licenciatura em Ciências Biológicas experiências didáticas que possam ser utilizadas futuramente em suas práticas pedagógicas.

\section{REFERÊNCIAS}

ANDRETTA, V.; MACEDO, R. L. G.; VITORINO, M. R.; MARTINS, G. S. Sinalização de trilhas: importância e eficiência. 2006. 13 p. Disponível em: http://www.scribd.com/doc/11566793/SINALIZACAO-DE-

TRILHASIMPORTANCIA-E-EFICIENCIA. Acesso 10 dez. 2019.

ARAÚJO JÚNIOR, A. C. R., SANTOS, A. R.; PEREIRA, R. L., OLIVEIRA, F. D. Práticas ambientais no Parque Ecológico Bosque dos Papagaios, Boa Vista/RR. Geo UERJ. 2018. Disponível em: https://www.epublicacoes.uerj.br/index.php/geouerj/article/view/30187/27308. Acesso $10 \mathrm{dez} .2019$.

BARBOSA, RI, CAMPOS, C. 2011. Detection and geographical distribution of clearing areas in the savannas ('lavrado') of Roraima using Google Earth web tool. Journal of Geography and Regional Planning, 4: 122-136.

BARBOSA, R. I.; CAMPOS, C.; PINTO, F.; FEARNSIDE, P. M. The "Lavrados" of Roraima: Biodiversity and Conservation of Brazil's Amazonian Savannas. Functional Ecosystems and Communities. 1(1). 2011. p. 29-41.

BARBOSA, R. I.; FEARNSIDE, P. M. Fire frequency and area burned in the Roraima savannas of Brazilian Amazonia. Forest ecology and management, 204. 2005. p. 371-384.

CALlEGARO, A. R. Trilhas ecológicas como ferramenta nas aulas de Ciências. VI Encontro Regional Sul de Ensino de Biologia (EREBIO-SUL). XVI Semana Acadêmica de Ciências Biológicas. Disponível em:

http://www.santoangelo.uri.br/erebiosul2013/anais/wpcontent/uploads/2013/07/poster/13351_151_Alfieri_Roberto_Callegaro.pdf. Acesso em: 10 Maio de 2019.

CARDOSO, F. S. A. A feira do produtor rural e a área verde escolar como espaços educativos para abordar educação ambiental e cidadania com professores e alunos da escola estadual Oswaldo Cruz, Boa Vista-RR. Dissertação apresentada ao Mestrado Profissional em Ensino de Ciências da Universidade Estadual de Roraima. 2019. Disponível em: https://uerr.edu.br/ppgec/wpcontent/uploads/2019/06/Disserta\%C3\%A7\%C3\%A3o-Francisca-Silvana.pdf. Acesso em: 10 Maio de 2019. 
GOHN, M. G. Educação Não Formal e o Educador Social: atuação no desenvolvimento de projetos sociais. São Paulo: Cortez, 2010.

FRITZEN, A. Monitoria na área de Botânica: Uma possibilidade de Ensino e Aprendizagem. Revista Insignare Scientia - RIS. Vol. 2, n. 3 - Edição Especial: Ciclos Formativos em Ensino de Ciências. 2019. Disponível em: https://periodicos.uffs.edu.br/index.php/RIS/article/view/11178/7244. Acesso em: 7 de Dezembro de 2019.

JACOBUCCI, D. F. C. Contribuições dos espaços não-formais de educação para a Formação da cultura científica. 2008. Disponível em: file://C:/Users/USUARIO/Downloads/20390-76872-1-PB.pdf. Acesso em: 26 Jun. 2019.

LAU, P. F. R. Peripatéticos do século XXI: ensinando ciências no Bosque dos Papagaios. Dissertação de Mestrado em Ensino de Ciências - Universidade Estadual de Roraima - UERR. 2014. Disponível em: https://uerr.edu.br/ppgec/wpcontent/uploads/2017/08/DISSERTA\%C3\%87\%C3\%83O-2014-PEURIS-FRANKRODRIGUES-LAU.pdf. Acesso em: 22 de maio de 2019.

LAU, P. F. R.,et al,. Mediação docente e ensino de Ciências em espaço não formal em Boa Vista: análise e perspectivas do Bosque dos Papagaios. Atas do IX Encontro Nacional de Pesquisa em Educação em Ciências - IX ENPEC Águas de Lindóia, SP 10 a 14 de Novembro de 2013. 2013. Disponível em: http://abrapecnet.org.br/atas_enpec/ixenpec/atas/resumos/R0695-1.pdf.. Acesso em: 26 Maio de 2019.

LORENZETTI, L.; DELIZOICOV, D. Alfabetização científica no contexto das séries. Ensaio - Pesquisa em educação em ciências, v.3, n.1, jun. 2001.

MARANDINO, M. Museus de ciências, coleções e educação: relações necessárias. Museologia e Patrimônio, v. 2, 2009. p. 1-12. Disponível em: http://revistamuseologiaepatrimonio.mast.br/index.php/ppgpmus/article/view/63/68.

Acesso em 23 de Agosto de 2019.

OLIVEIRA, C. B.; GONZAGA, L. T.; GOMES, E. C.; TERÁN, A. F. Espaços educativos: Oportunidade de uma prática educativa problematizadora. Revista Reamec, Cuiabá - MT, v. 7, n. 1, Jan/Jun. Disponível em: http://periodicoscientificos.ufmt.br/ojs/index.php/reamec/article/view/6962. Acesso em: 20 de maio de 2019.

PIN, J. R. O.; ROCHA, M. B. Espaços educativos não formais na perspectiva da formação continuada de professores de ciências do município de castelo (ES). Experiências em ensino de Ciências, v. 12, No. 1. 2017. Disponível em: 
http://www.if.ufmt.br/eenci/artigos/Artigo_ID338/v12_n1_a2017.pdf. Acesso em: 03 Setembro 2019.

REIS, T. R.; GHEDIN, E. L.; SILVA, S. J. R. O uso de espaços formais e não formais de educação em estratégias didáticas com enfoque CTS. IV Simpósio Nacional de Ensino de Ciências em novembro de 2014. Disponível em: http://sinect.com.br/anais2014/anais2014/artigos/educacao-cientifica-e-tecnologica-eestudos-cts/01409600992.pdf. Acesso em: 14 de Junho de 20

ROCHA, S. C. B.; TÉRAN, A. F. O uso de espaços não-formais como estratégia para o Ensino de Ciências. Manaus: UEA/Escola Normal Superior/PPGEECA. 2010. 136 p. Disponível em: file:///C:/Users/USUARIO/Downloads/2010_08_31_LivroUsodeEspacosnaoFormaisde Ensino.pdf. Acesso em: 02 de Setembro de 2019.

SOUSA, M. S. M.; REIS, T. R.; RIZZATTI, I. M. Parque ecológico Bosque dos Papagaios: uma proposta para um ensino de ciências em espaço não formal. Ensino em Re-Vista. v 25, n 2. 2018. p. 410-430. Disponível em: http://www.seer.ufu.br/index.php/emrevista/article/view/43276/22715. Acesso em: 02 de Setembro de 2019.

VIDAL, W. N.; VIDAL, M. R. R. Botânica - Oragnografia. Quadros Sinóticos Ilustrados de Fanerógamos. $4^{\circ}$ edição. Editora UFV:Viçosa. 2006. 124 p. 